\title{
MEDIA PEMBELAJARAN BERBAHAN LOOSE PART DALAM PEMBELAJARAN EKSAK DI MI KEDUNGWULUH LOR
}

\author{
Sri Muryaningsih ${ }^{1}$ \\ ${ }^{1}$ Universitas Muhammadiyah Purwokerto
}

\section{Article Info}

Article history:

Accepted April 22, 2021

Published April, 2021

Keywords:

learning media, loose part

\begin{abstract}
Media is a tool that is used to convey informatiabson from the sender of the message to the recipient of the message. Learning media is defined as a tool used by teachers to convey learning material to students, and a means of communication between students and students. There are problems such as the use of learning media at MI Muhammadiyah Kedungwuluh Lor is not optimal. This activity seeks to provide assistance in creating and using learning media, especially in exact subjects so that student learning outcomes are getting better.
\end{abstract} All right reserved

\section{Corresponding Author:}

Sri Muryaningsih

Program Studi Pendidikan Guru Sekolah Dasar,

Universitas Muhammadiyah Purwokerto,

Jl. KH. Ahmad Dahlan, Po. Box 202 Purwokerto, Banyumas, Indonesia.

Email: cicihwiarsih.umpwt@gmail.com

\section{How to Cite:}

Muryaningsih, S. (2021). Media Pembelajaran Berbahan Loose Part Dalam Pembelajaran Eksak Di Mi Kedungwuluh Lor. Khazanah Pendidikan-Jurnal Ilmiah Kependidikan (JIK), 15(1), 84-91.

\section{PENDAHULUAN}

Ilmu yang sebaiknya dipelajari siswa di sekolah terdiri dari ilmu eksak dan ilmu non eksak. Ilmu eksak menurut KBBI adalah bidang ilmu tentang hal-hal yang bersifat konkret yang dapat diketahui dan diselidiki berdasarkan percobaan serta dapat dibuktikan dengan pasti. Sedangkan ilmu non eksak dalam KBBI adalah ilmu yang bukan eksata. Ilmu eksakta contohnya adalah: matematika dan Ilmu Pengetahuan Alam (IPA).

Pembelajaran matematika dan IPA merupakan salah satu mata pelajaran yang ada di Sekolah Dasar (SD) dan matematika merupakan salah satu mata pelajaran yang sangat penting bagi siswa karena memiliki peran penting dalam kehidupan sehari-hari yaitu matematika digunakan manusia untuk memecahkan masalahnya dalam kehidupan seharihari (Suwaningsih, 2006: 9). 
Pada umumnya matematika masih sulit dipahami oleh sebagian siswa dan menganggap bahwa matematika itu merupakan mata pelajaran yang sulit. Begitu juga dengan mata pelajaran IPA. Presepsi negatif seperti ini tidak bisa diacuhkan begitu saja, tetapi harus diatasi dengan membuat matematika menjadi pelajaran yang tidak sulit dan menyenangkan bagi siswa.

Pelaksanaan pembelajaran di SD guru harus mampu memahami karakteristik siswa dalam belajar. Susanto (2013:183-184) mengemukakan teori kognitif Piaget, yaitu pada siswa sekolah dasar (usia 7-8 tahun hingga 12-13 tahun) termasuk pada tahap operasional konkret. Berdasarkan teori kognitif Piaget, hal ini berarti usia anak sekolah dasar masih sulit untuk memahami matematika yang bersifat abstrak. Sehingga, guru harus bisa menentukan metode/ strategi/ media yang sesuai agar memudahkan siswa untuk belajar.

Penggunaan media pembelajaran di MI Muhammadiyah Kedungwuluh Lor perlu diterapkan lebih optimal oleh semua guru, khususnya pada mata pelajaran matematika dan IPA. Guru jarang menggunakan media pembelajaran dikarenakan mahal dan membutuhkan waktu yang lama dalam pembuatannya.

Berdasarkan masalah yang ada maka perlu adanya pendampingan dalam pembuatan dan penggunaan media pembelajaran. Media pembelajaran yang dibuat dikhususkan untuk media pembelajaran pada mata pelajaran matematika dan IPA dengan menggunakan bahan loose part.

\section{HASIL DAN PEMBAHASAN}

\section{a. Media}

Pengertian media pembelajaran disampaikan oleh banyak ahli. Menurut Sadiman (2011:7) media adalah segala sesuatu yang dapat digunakan untuk menyalurkan pesan dari pengirim ke penerima sehingga dapat merangsang pikiran, perasaan, perhatian dan minat serta perhatian pesesrta didik sedemikian rupa sehingga proses belajar terjadi. Menurut Arsyad (2007:3) pengertian media dari kata media bersal dari bahasa latin yaitu medis yang secara harfiah berarti "tengah" perantara, atau "pengantar". Gerlach dan Ely (1971) dalam (Arsyad,2007: 3) mengatakan bahwa media apabila dipahami secara garis besar adalah manusia, materi atau kejadian yang membangun kondisi membuat siswa mampu memperoleh pengetahuan, keterampilan dan sikap.

Pendapat Smaldino (2005) dalam (Anitah,2008: 1) mengatakan bahwa media adalah sesuatu alat komunikasi dan sumber informasi. Berasal dari bahasa latin "medium" yang berarti "antara", media menunjuk pada segala sesuatu tersebut membawakan pesan untuk suatu tujuan pembelajaran. Menurut Kustandi dan Sutjipto (2016:19) kedudukan media dalam sistem pembelajaran yaitu sebagai alat bantu, alat penyalur pesan, alat penguatan (reinforcement) dan wakil guru dalam menyampaikan informasi secara lebih teliti, jelas dan menarik. Dengan adanya media pembelajaran akan menyalurkan pesan kepada peserta didik agar lebih jelas dan mempermudah proses pembelajaran.

\section{b. Media pembelajaran}

Media pembelajaran menurut Indriana dalam Vebimawarti (2017) menyatakan bahwa media pengajaran adalah semua bahan dan alat fisik yang memungkinkan digunakan untuk mengimplementasikan pengajaran dan memfasilitasi siswa terhadap sasaran atau tujuan pengajaran. Media pembelajaran yang digunakan dalam proses pembelajaran akan memperjelas materi yang disampaikan oleh guru. Peranan media dalam pembelajaran adalah meletakkan ide-ide konsep dasar, sehingga dengan bantuan media yang sesuai, peserta didik dapat memahami ide-ide dasar yang melandasi sebuah konsep dan dapat menarik suatu kesimpulan dari hasil pengamatannya. 
Kata media berasal dari bahasa Latin dan merupakan bentuk jamak dari kata medium yang dapat diartikan sebagai peratara atau pengantar. Lesle J. Briggs (Sanjaya, 2013: 204) menyatakan media pembelajaran adalah alat untuk memberi perangsang bagi siswa supaya teradi prses belajar. Rossi dan Breidle (Sanjaya, 2013: 204) mengemukakan bahwa media pembelajaran adalah seluruh alat dan bahan yang dapat dipakai untuk tujuan pendidikan, seperti radio, televisi, buku, koran, majalah, dan sebagainya. Pengertian media pembelajaran menurut kedua ahli tersebut dapat disimpulkan bahwa media pembelajaran merupkan seluruh alat dan bahan yang digunakan sebagai perantara atau memberi rangsangan kepada siswa mengenai pembelajaran agar tujuan dari sebuah proses pembelajaran dapat tercapai.

Menurut Live dan Lepts dalam Akbar (2013: 119), fungsi media secara visual antara lain: 1. Fungsi atensi, yakni menarik perhatian peserta didik untuk berkonsentrasi pada isi pelajaran, 2. Fungsi afeksi, yakni menciptakan perasaan senang peserta didik, dan 3. Fungsi kognisi, yaitu alat bantu memahami dan menginat informasi. Dengan menggunakan media dalam pembelajaran diharapkan akan tumbuh minat belajar pada diri peserta didik, dan peserta didik akan lebih dapat memahami konsep yang disajikan.

Penyampaian informasi dalam pembelajaran tidak hanya melalui bahasa saja namun bisa menggunakan media. Peranan media pembelajaran sangat diperlukan dalam suatu kegiatan belajar mengajar. Seorang guru dapat menggunakan berbagai media dalam memberikan informasi kepada siswa agar siswa lebih memahaminya. Menurut Sanjaya (2013: 207) media pembelajaran memiliki fungsi, yaitu:

1) Menangkap suatu objek atau peristiwa-peristiwa tertentu.

2) Memanipulasi keadaan, peristiwa atau objek tertentu.

3) Menambah gairah dan motivasi belajar siswa.

4) Media pembelajaran memiliki nilai praktis sebagai berikut:

a) Media dapat mengatasi keterbatasan pegalaman yang dimiliki siswa.

b) Media dapat mengatasi batas ruang kelas.

c) Media dapat memugkinkan teradinya iteraksi langung antara peserta didik dengan lingkungan.

d) Media dapat menghasilkan keseragaman pengamatan.

e) Media dapat mengembangkan konsep dasar yang benar nyata, dan tepat.

f) Media dapat membangkitkan motivasi dan merangsang peserta didik untuk belajar dengan baik.

g) Media dapat membangkitkan keinginan dan minat baru.

h) Media dapat mengkontrol kecepatan belajar siswa.

i) Media dapat memberikan pengalaman yang menyeluruh dari hal-hal yang konkret sampai yang abstrak.

Fungsi media pembelajaran secara umum berfungsi sebagai alat dalam pembelajaran sehingga dapat mengahantarkan pada tujuan pembelajaran. Media pembelajaran akan memberikan hasil yang optimal apabila digunakan secara tepat, dalam arti sesuai dengan materi pelajaran dan bersifat mendukung.

Media pembelajaran dapat diklasifikasikan menjadi beberapa klasifikasi tergantung dari sudut mana melihatnya. Berikut klasifikasi media pembelajaran menurut Sanjaya (2013: 211) yaitu:

1) Dilihat dari sifatnya, media dapat dibagi ke dalam:

a) Media auditif, yaitu media yang hanya dapat didengar saja seperti radio atau rekaman suara.

b) Media visual, yaitu media yang hanya dapat dilihat saja dan tidak mengandung usur suara, misalnya slide, foto, lukisan, gambar, dan berbagai bentuk bahan yang dicetak seperti media grafis. 
c) Media audivisual, yaitu media yang selain mengandung usur suara juga mengandung unsur gambar yang dapat dilihat, misalnya rekaman vidio, film, dan lain sebagainya.

2) Dilihat dari kemampuan jangkauanya, media dapat pula dibagi ke dalam:

a) Media yang memiliki daya iput yang luas dan serentak seperti radio dan televisi.

b) Media yang mempuyai daya input yang terbatas oleh ruang dan waktu, seperti slide, film, vidio, dan lain sebagainya.

3) Dilihat dari cara pemakaiannya, media dapat dibagi ke dalam:

a) Media yang dapat diproyeksikan, seperti film, slide, film strip, trasparasi dan lain sebagainya.

b) Media yang tidak diproyeksikan, seperti gambar, foto, lukisan, radio, dan lain sebagainya.

Berbagai klasifikasi media pembelajaran di atas, media pembelajaran tidak selamanya membuahkan hasil belajar siswa lebih cepat, lebih meningkat dan lebih menarik. Adapula media pembelajaran yang terkadang membuat siswa gagal dalam belajarnya. Hal tersebut dikarenakan kadang guru dalam memilih media pembelajaran kurang cermat dan kurang sesuai dengan kondisi siswa.

Menurut Anwar (2018: 122) dalam memilih dan membuat media pemelajaran agar memperoleh hasil yang baik, maka seorang guru harus mempertimbangkan beberapa persyaratan, antara lain:

1) Tahan lama (dibuat dari bahan yang cukup kuat).

2) Bentuk dan warnanya menarik perhatian siswa.

3) Sederhana dan mudah dikelola.

4) Ukurannya sesuai dengan ruang belajar mengajar.

5) Dapat menyajikan konsep baik berbentuk riil, gambar, maupun diagram.

6) Sesuai dengan konsep yang akan dibahas.

7) Dapat memperjelas konsep bukan sebaliknya.

8) Peragaan itu harus mampu menjadi dasar bagi tumbuhnya konsep berpikir abstrak bagi siswa.

9) Menjadikan siswa belajar secara aktif dan mandiri dengan memanipulasi dan merekayasa alat peraga.

10) Bila mungkin alat peraga tersebut bisa mempunyai banyak faedah dalam proses pembelajaran.

Dapat disimpulkan bahwa seorang guru harus bisa memahami pola penggunaan media pembelajaran secara tepat. Seorang guru harus membuat media pembelajaran dengan menyesuaikan konsep yang disampaikan dalam pembelajaran dengan tujuan untuk memudahkan siswa dalam memahami konsep yang diajarkan. Oleh karena itu dengan adanya media dalam belajar dapat membantu siswa untuk meningkatkan prestasi belajarnya.

Setiap media pembelajaran memiliki kegunaan yang berbeda-beda. Menurut Sadiman (2011:17) secara umum media pendidikan mempunyai kegunaan sebagai berikut:

1) Memperjelas penyajian pesan agar tidak terlalu bersifat verbalistis (dalam bentuk kata-kata tertulis atau tidak belaka).

2) Mengatasi keterbatasan ruang, waktu dan daya indera.

3) Penggunaan media pendidikan secara tepat dan bervariasi dapat mengatasi sikap pasif anak didik.

4) Dengan sifat yang unik pada tiap siswa ditambah lagi dengan lingkungan dan pengalaman yang berbeda, sedangkan kurikulum dan materi pendidikan ditentukan sama untuk setiap siswa, maka guru banyak mengalami kesulitan 
bilamana semuanya itu harus diatasi sendiri. hal ini akan lebih sulit bila latar belakang lingkungan guru dengan siswa juga berbeda.

Kegunaan media pembelajaran dalam kegiatan penyampaian materi semakin jelas, karena media pembelajaran menjadi sarana untuk penyampaian materi dan memberikan kesan atau pembelajaran yang bermaksan kepada siswa. Guru dalam kegiatan pembelajaran biasanya menggunakan beberapa media pembelajaran yang sesuai dengan materi yang akan diajarkan. Sudjana dan Ahmad (2005:3) menjelaskan jenis-jenis media pembelajaran yang biasa digunakan guru dalam proses pembelajaran, anatar lain:

1) Media dua dimensi (medai grafis) yakni media pembelajaran yang mempunyai ukuran panjang dan lebar. Media grafis seperti ; gambar, foto, grafik, bagan atau diagram, poster, kartu komik dan lain-lain.

2) Media tiga dimensi yaitu dalam bentuk model susun, model kerja, mock up, diorama dan lain-lain.

3) Media proyeksi seperti slide, film, film strips, penggunaan OHP dan lain-lain.

4) Penggunaan lingkungan sebagai media pembelajaran.

Media pembelajaran dapat digunakan dalam proses pembelajaran dengan baik jika pemilihan dan penggunaannya disesuaikan dengan materi dan karakteristik siswa yang menerima pesan.

\section{c. Loose part}

Loose part merupakan bahan yang dapat dipindahkan, dibawa, digabungkan, dirancang ulang, dipisahkan dan disatukan kembali dengan berbagai cara. Media dengan menggunakan bahan loose part dapat dimanfaatkan tanpa batas oleh siapa pun. Media dengan menggunakan bahan loose part dapat digunakan untuk meningkatkan kemampuan: pemecahan masalah, kreativitas, konsentrasi, motorik halus, motorik kasar, sain (Science), pengembagangan bahasa (Literacy), seni (Art), logika berfikir matematika (Math), Teknik (Engineering), Tecnologi (Technology).

Bahan-bahan yang dapat dimanafaatkan untuk membuat media dari bahan loose part: bahan dasar alam, plastik, logam, penggunaan kembali kayu dan bambu, kaca dan keramik, benang dan kain, bekas kemasan.

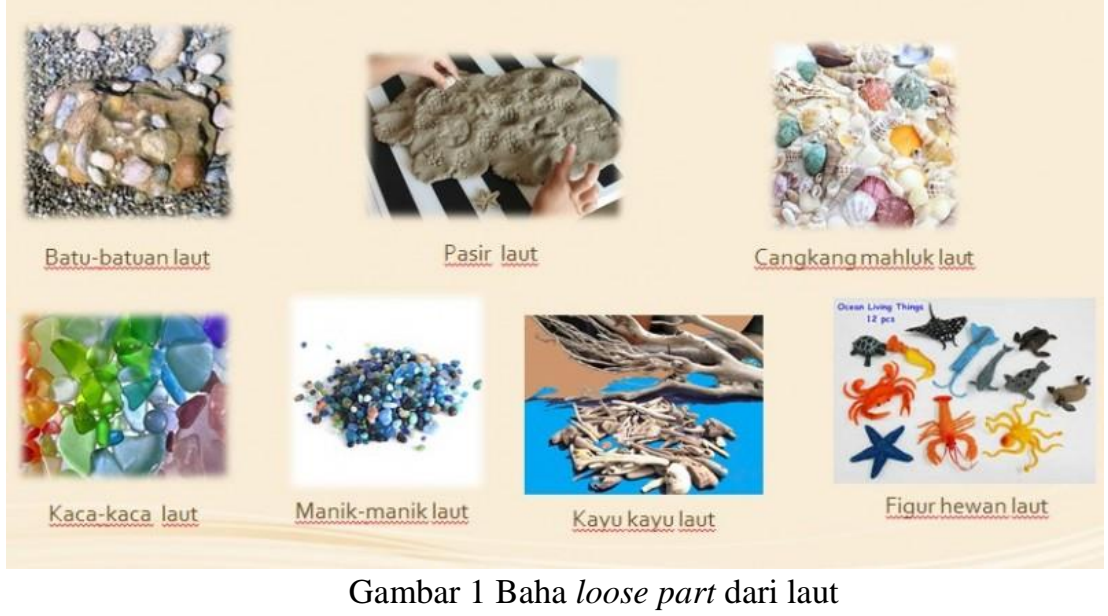

Adapun manfaat media dari bahan loose part adalah:

1) Meningkatkan tingkat permainan kreatif dan imajinatif anak

2) Meningkatkan sikap kooperatif dan sosialisasi anak

3) Anak menjadi lebih aktif secara fisik

4) Mendorong kemampuan komunikasi dan negosiasi

5) Memberikan pengalaman bermain yang kaya kualitas 


\section{d. Pembelajaran eksak}

Pembelajaran eksak atau mata pelajaran eksak seperti mata pelajaran matematika dan IPA dalam penyampaian materinya sangat membutuhkan media pembelajaran. Media pembelajaran yang disusun sebaiknya berasal dari bahan loose part. Karena bahan loose part mudah untuk dibawa, disusun ataupun dimanfaatkan dalam kegiatan pembelajaran.

Adapun media pembalajaran dari bahan loose part yang dipaparkan tentang cara pembuatan dan penggunaannya dalam pembelajaran.

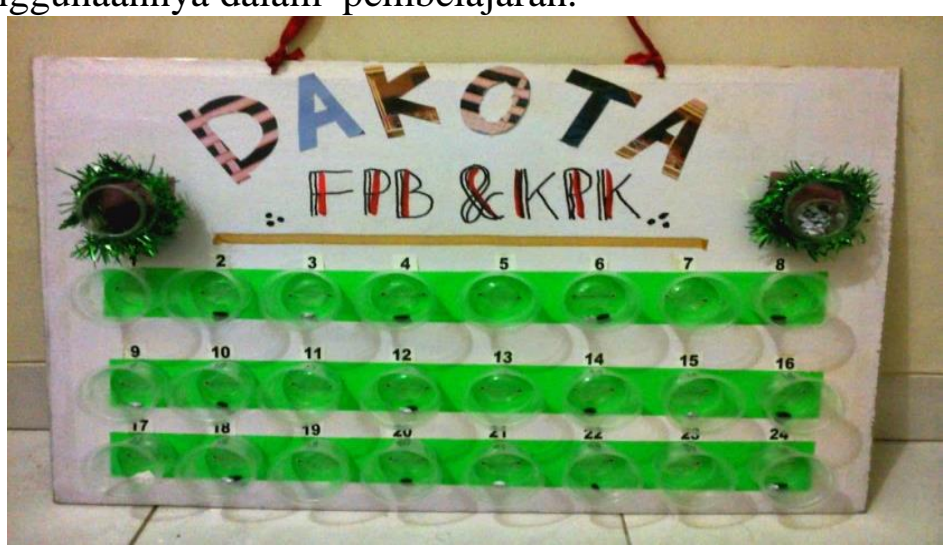

Gambar 2 Papan Dakota KPK dan FPB

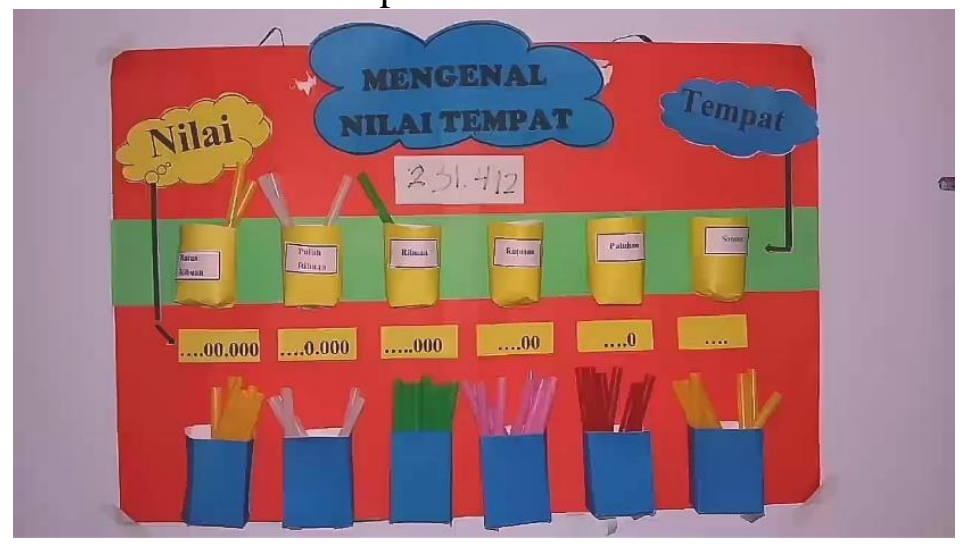

Gambar 3 Papan Nilai Tempat 


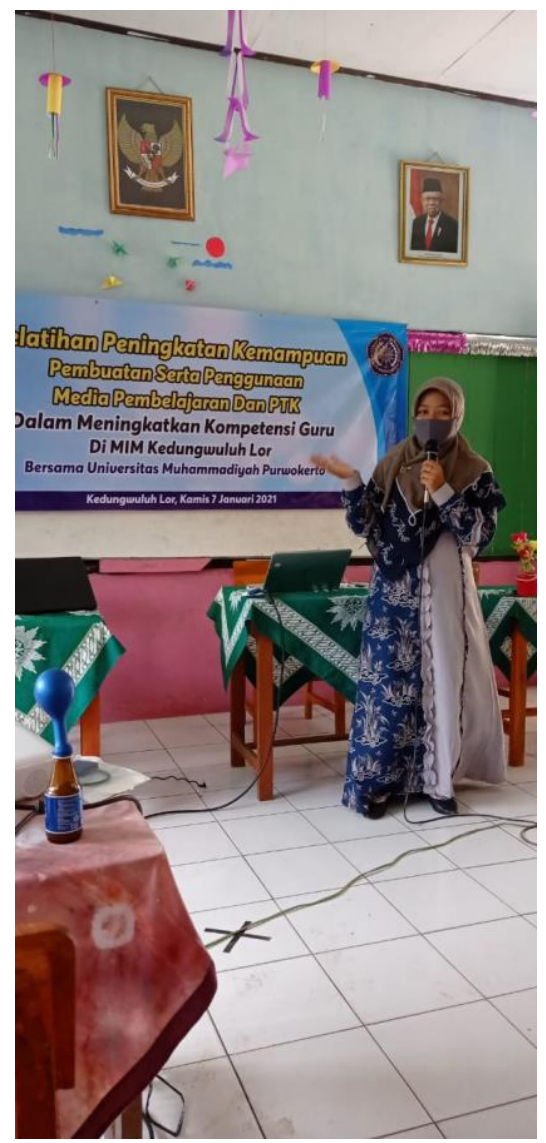

Gambar 3 Pembuktian bahwa makhluk hidup bernafas

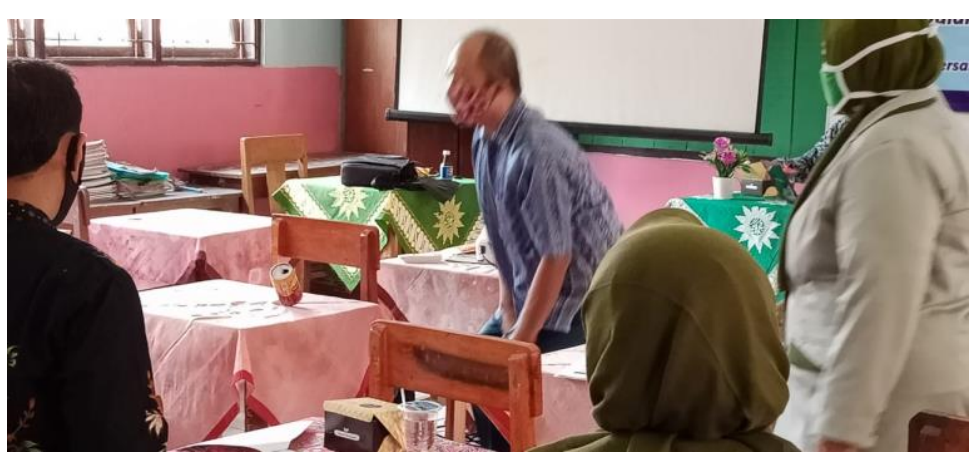

Gambar 4 Botol bekas untuk pembuktian bahwa air menempati ruang 


\section{KESIMPULAN}

MIM Kedungwuluh Lor merupakan salah satu lembaga pendidikan Sekolah Dasar yang berada di Kabupaten Banyumas yang merencanakan dan melaksanakan kegiatan belajar mengajar. Kepala sekolah dan guru selaku berusaha memperbaiki diri dengan meningkatkan kualifikasi pendidikan maupun mengikuti pelatihan dan workshop untuk meningkatkan kemampuan diri. Semakin baik potensi yang dimiliki guru maka akan semakin baik kualitas pembelajaran yang dilakukan. Pembelajaran yang baik dengan menggunakan media pembelajaran untuk memberikan pengalaman langsung dan pembelajaran yang bermakna untuk siswa. Dengan adanya pembelajaran yang bermakna siswa akan memiliki hasil belajar yang baik.

\section{DAFTAR PUSTAKA}

Akbar, Sa'dun. 2013. Instrumen Perangkat Pembelajaran. Bandung: Remaja Rosdakarya Anitah,S. (2009). Media Pembelajaran. Surakarta: LPP UNS dan UNS Press

Anwar, Muhammad. (2018). Menjadi Guru Profesional. Jakarta: Prenadamedia Group Arsyad, A. (2007). Media Pembelajaran. Jakarta : PT. Grafindo Persada

Eksak (Def.1)(n.d). Dalam Kamus Besar Bahasa Indonesia (KBBI) Online. Diakses melalui https://kbbi.web.id/eksak, 10 April 2021

Non eksak (Def.1)(n.d). Dalam Kamus Besar Bahasa Indonesia (KBBI) Online. Diakses melalui https://kbbi.web.id/eksak, 10 April 2021

https://buhrin.gurusiana.id/article/2019/10/pembelajaran-berbasis-konten-steam-dan-loosepart-1729039 diakses pada 10 April 2021

Kustandi \& Bambang . 2016. Media Pembelajaran . Bogor: Ghalia Indonesia

Ruhyana. (2016). Analisis Kesulitan Siswa Dalam Pemecahan Masalah Matematika. Jurnal Computech \& Bisnis. 10 (2): 106-118.

Sadiman, Arief S dkk. 2011: Media Pendidikan Pengertian, Pengembangan dan Pemanfaatannya. Jakarta: Pustekkom Dibud dan PT Raja Grafindo Persada

Said \& Andi. 2015. 95 Strategi Mengajar Multiple Intelligences. Jakarta: Kencana

Sanjaya, Wina. (2013). Perencanaan dan Design Sistem Pembelajaran. Jakarta: Prenadamedia Group.

Sudjana \& Ahmad. 2005. Media Pengajaran. Bandung: Sinar Baru Algensindo

Suwaningsih, Erna. (2006). Model Pembelajaran Matematika. Bandung: UPI Press.

Susanto, Ahmad. (2013). Teori Belajar dan Pembelajaran di Sekolah Dasar. Jakarta: Prenadamedia Group.

Vebimawarti, Putik. Pengembangan Media Permainan Matematika Kartu Cerdas Tangkas Bilangan Romawi. Jurnal Dinamika Pendidikan Dasar. 10 (1) September 2017: 8-12

Widowati \& Mulyani. 2014. " Penggunaan Media Ular Tangga untuk Meningkatkan Hasil Belajar Siswa pada Tema Hiburan”. Journal PGSD FIP Universitas Surabaya, Vol 02 No 01 diakses pada tanggal 15 Desember 2018

Yaumi. 2014: Pendidikan Karakter Landasan, Pilar \& Implementasi.Jakarta: Prenadamedia Group

Zubaedi. 2011. Desain Pendidikan Karakter. Jakarta: Kencana Prenada Media Group 